\title{
Is there a link between hyperuricemia, morning blood pressure surge, and non-dipping blood pressure pattern in metabolic syndrome patients?
}

This article was published in the following Dove Press journal: International Journal of Nephrology and Renovascular Disease 25 April 2013

Number of times this article has been viewed

\author{
Emre Tutal' \\ Burak Sayın' \\ Derun Taner Ertugrul ${ }^{2}$ \\ Avsin Ibis' \\ Siren Sezer' \\ Nurhan Özdemir' \\ 'Department of Nephrology, Baskent \\ University Hospital, ${ }^{2}$ Department \\ of Endocrinology and Metabolism, \\ Keçiören Training and Research \\ Hospital, Ankara, Turkey
}

Background: Hypertensive patients usually have a blunted nocturnal decrease, or even increase, in blood pressure during sleep. There is also a tendency for increased occurrence of cardiovascular events between 6 and 12 am due to increased morning blood pressure surge (MBPS). Co-occurrence of metabolic syndrome (MetS) and hypertension is also a common problem. Hyperuricemia might trigger the development of hypertension, chronic renal failure, and insulin resistance. In this study, we aimed to determine whether there is a relationship between hyperuricemia, MetS, nocturnal blood pressure changes, and MBPS.

Method: A total of 81 newly diagnosed hypertensive MetS patients were included in this study. Ambulatory blood pressure monitoring of patients was done and patients' height, weight, and waist and hip circumferences were recorded. Fasting blood glucose (FBG), lipid profile, creatinine, potassium, uric acid, hematocrit levels were studied.

Results: Non-dipper (ie, those whose blood pressure did not drop overnight) patients had higher waist-hip ratios (WHR) $(P=0.003)$, uric acid $(P=0.0001)$, FBG $(P=0.001)$, total and low-density lipoprotein cholesterol levels $(P=0.0001)$. Risk analysis revealed that hyperuricemia was a risk factor for non-dipping pattern $(P<0.0001$, odds ratio $=8.1,95 \%$ confidence interval $=1.9-33.7)$. Patients in the highest quadrant for uric acid levels had higher FBG $(P=0.001)$, low-density lipoprotein cholesterol $(P=0.017)$, WHR $(P=0.01)$, MBPS $(P=0.003)$, and night diastolic blood pressure compared with lowest quadrant patients $(P=0.013)$. Uric acid levels were also positively correlated with night ambulatory blood pressure (ABP) $(\mathrm{r}=0.268$, $P=0.05)$, night diastolic blood pressure $(\mathrm{r}=0.3, P=0.05)$, and MBPS $(\mathrm{r}=0.3, P=0.05)$.

Conclusion: Evaluation of hypertensive patients should also include an assessment of uric acid level and anthropometric measurements such as abdominal obesity. Hyperuricemia seems to be closely related to undesired blood pressure patterns and this may signal to the clinician that an appropriate therapeutic approach is required.

Keywords: hypertension, uric acid, non-dipper

\section{Introduction}

The incidence of hypertension (HT) increases with age and nearly half of the population aged 60-69 years and three-quarters of those aged over 70 years are hypertensive. Ischemic heart disease and stroke risk increase when systolic blood pressure (SBP) rises above $115 \mathrm{mmHg}$ and diastolic blood pressure (DBP) rises above $75 \mathrm{mmHg}$. ${ }^{1}$ Healthy, normotensive individuals have a 10\%-20\% nocturnal decrease in blood pressure (BP) during the night. This decrease is under the influence of psychosocial, behavioral, and neurohumoral (sympathetic nervous system, renin-angiotensin system) factors. ${ }^{2-4}$ Hypertensive patients usually have a blunted nocturnal decrease, or even increase, in BP during sleep. This has been reported to increase the risk for 
cardiovascular diseases. It is well known that there is a tendency for increased occurrence of cardiovascular events between 6 and 9 am, just after waking from sleep. ${ }^{5,6}$ This is usually a result of increased morning blood pressure surge (MBPS) in hypertensive individuals and 24-hour ambulatory blood pressure monitoring (ABPM) is the gold standard to evaluate these nocturnal changes and MBPS in hypertensive patients.

Metabolic syndrome (MetS) is another cardiovascular risk factor that is very common in hypertensive patients. In fact, presence of HT is one of the criteria for diagnosis of MetS according to the Adult Treatment Panel III. ${ }^{7}$ Presence of three of the following five conditions is needed for diagnosing a patient as MetS: abdominal obesity (waist circumference $\geq 102 \mathrm{~cm}$ in males and $\geq 88 \mathrm{~cm}$ in females), HT (SBP $\geq 130 \mathrm{mmHg}$ and/or DBP $\geq 85 \mathrm{mmHg}$ ), fasting blood glucose $(\mathrm{FBG}) \geq 110 \mathrm{mg} / \mathrm{dL}$, triglycerides (TGs) $\geq 150 \mathrm{mg} / \mathrm{dL}$, and high-density lipoprotein (HDL) $<40 \mathrm{mg} / \mathrm{dL}$ in males and $<50 \mathrm{mg} / \mathrm{dL}$ in females. Insulin resistance (IR) is considered the main underlying problem in MetS. However, genetic factors, hyperuricemia, nutritional behaviors, and lifestyle have also been speculated to have effects. ${ }^{8,9}$ Further, although hyperuricemia is underestimated by some clinical practitioners, ${ }^{10,11}$ some reports link presence of hyperuricemia with development of HT, chronic renal failure, IR, diabetes mellitus (DM), and endothelial dysfunction (ED). In this study, we aimed to determine whether there is a relationship between hyperuricemia, MetS, nocturnal BP changes, MBPS, and abdominal obesity. Therefore, we suggest decreasing uric acid levels is a target for treatment of HT, chronic renal failure, IR, DM, and ED patients.

\section{Patients and methods}

A total of 81 newly diagnosed hypertensive patients (61 female; age [mean \pm standard deviation (SD)] $58.4 \pm 9.4$ years) were included. None of the patients had any history of HT, hyperlipidemia, DM, gouty arthritis, cardiovascular disease, or stroke, and none was taking any medications for any of these clinical conditions. Patients with an office BP measurement $\geq 140 / 90 \mathrm{mmHg}$ were diagnosed as hypertensive according to seventh report of the Joint National Committee on Prevention, Detection, Evaluation, and Treatment of High Blood Pressure criteria ${ }^{12}$ and were evaluated for inclusion. Individuals who also fulfilled two further Adult Treatment Panel III criteria were included in the study and ABPM was undertaken on these participants. An Oscar ${ }^{\mathrm{TM}} 2$ Ambulatory Blood Pressure Monitor (SunTech Medical ${ }^{\circledR}$, Raleigh, USA
ABD) was used for the ABPM. BP measurements were done at 15-minute periods between 7 am and $11 \mathrm{pm}$ and at 30-minute periods between $11 \mathrm{pm}$ and $7 \mathrm{am}$. Patients were asked to record their sleep and waking times and these records were taken under consideration when making necessary calculations. In case of insufficient measurements or technical problems, the ABPM was repeated.

The resultant ABPM reports were evaluated to define dipper versus (vs)non-dipper status (ie, whether patients' BP did or did not, respectively, decrease during the night). Individuals with a decrease in night/sleep time mean SBP $>10 \%$ compared with morning mean SBP were considered dipper patients and all others were considered non-dipper patients. ${ }^{13}$ MBPS was calculated by subtracting the mean SBP value of the hour that the lowest SBP was measured during sleep from the second hour SBP following waking. ${ }^{14}$ Office, daytime, night, and 24-hour mean SBP and DBP values were also recorded. Office BP measurements were done by the same person, following the guidance of the seventh report of the Joint National Committee on Prevention, Detection, Evaluation, and Treatment of High Blood Pressure, on at least two separate occasions on different days.

Anthropometric measurements included height, weight, waist and hip circumference measurements. All measurements were done by the same person. Waist circumference measurements were acquired while patients were standing up and breathing slowly, between the upper end of the iliac crest and the lower end of the lowest rib. Hip measurements were also done while patients were standing, from the widest point of the hip. ${ }^{15}$ Body mass index and a waist-hip ratio (WHR) were calculated and recorded for each patient.

Blood glucose, lipid profile (total cholesterol [Tcol], HDL cholesterol, low-density lipoprotein [LDL] cholesterol, TG), creatinine, potassium, uric acid, hematocrit and thyroid-stimulating hormone levels were studied from an 8-hour fasting blood sample using standard laboratory techniques. The hyperuricemia threshold was accepted as $6 \mathrm{mg} / \mathrm{dL}$.

Statistical analyses were performed with SPSS software (v 11.0, IBM, Armonk, NY, USA). All numerical data presented here are expressed as the mean \pm SD. Data normality was analyzed by Kolmogorov-Smirnov test. All numerical variables with normal distribution are expressed here as mean $\pm \mathrm{SD}$, while variables with skew distribution are expressed as median, interquartile range. Categorical variables are given as percentages and were compared using the Chi-square test. Normally distributed numeric variables were compared with independent-samples Student's $t$-test, 
and skew distributed numeric variables were compared using the Mann-Whitney $U$ test. A $P$ value $<0.05$ was considered statistically significant.

\section{Results}

Demographic and anthropometric characteristics and laboratory and ABPM data for the study group are summarized in Table 1. Non-dipper patients had higher WHR $(0.92 \pm 0.09$ vs $0.87 \pm 0.06, P=0.003)$, uric acid $(5.0 \pm 1.3$ vs $3.7 \pm 0.9$, $P=0.0001)$, FBG (106.1 \pm 14.5 vs $94.6 \pm 13.9, P=0.001)$, Tcol and LDL cholesterol levels $(237.4 \pm 41.6$ vs $184.3 \pm 34.3$ and $153,45.5$ vs 97, 35, respectively, $P=0.0001$, Table 2 ). Risk analysis revealed that hyperuricemia (uric acid $>6 \mathrm{mg} / \mathrm{dL}$ ) was a risk factor for non-dipping pattern $(P<0.0001$, odds ratio $=8.1,95 \%$ confidence interval $=1.9-33.7$ ).

Further analysis revealed that patients in the highest quadrant for uric acid levels had higher FBG $(108.3 \pm 13.9$ vs $91.6 \pm 16.7, P=0.001)$, LDL cholesterol $(148,68$ vs $123,57 P=0.017)$ WHR $(0.92 \pm 0.09$ vs $0.85 \pm 0.06, P=0.01)$, MBPS $(44.3 \pm 9.8$ vs $35.6 \pm 7.2$, $P=0.003)$, and night DBP $(67.5 \pm 8.5$ vs $61.4 \pm 4.9$, $P=0.013$, Table 3 ) compared with those in the lowest quadrant. Uric acid levels were also positively correlated with night ambulatory blood pressure $(\mathrm{ABP})(\mathrm{r}=0.268, P<0.05)$,

Table I Demographic and clinical characteristics of study group $(\mathrm{N}=8 \mathrm{I})$

\begin{tabular}{|c|c|}
\hline $\operatorname{Sex}(M / F)$ & $20 / 61$ \\
\hline Age, mean \pm SD (years) & $58.4 \pm 9.4$ \\
\hline Office SBP, median, IC (mmHg) & $160.0,20.0$ \\
\hline Office DBP, median, IQR (mmHg) & $110.0,15.0$ \\
\hline ABPM daytime SBP, mean \pm SD $(\mathrm{mmHg})$ & $155.2 \pm 14.2$ \\
\hline ABPM daytime $\mathrm{DBP}$, mean $\pm \mathrm{SD}(\mathrm{mmHg})$ & $90.2 \pm 7.5$ \\
\hline ABPM night SBP, median, IQR (mmHg) & $138.0,16.8$ \\
\hline ABPM night $\mathrm{DBP}$, mean $\pm \mathrm{SD}(\mathrm{mmHg})$ & $63.3 \pm 8.2$ \\
\hline ABPM 24-hour SBP, mean \pm SD $(\mathrm{mmHg})$ & $152.1 \pm 13.4$ \\
\hline ABPM 24-hour DBP, mean \pm SD $(\mathrm{mmHg})$ & $84.8 \pm 6.9$ \\
\hline Morning blood pressure surge, mean $\pm \mathrm{SD}(\mathrm{mmHg})$ & $37.8 \pm 8.3$ \\
\hline Non-dipper, n, \% & $36,44.4$ \\
\hline Body mass index, mean $\pm \mathrm{SD}\left(\mathrm{kg} / \mathrm{m}^{2}\right)$ & $29.2 \pm 3.9$ \\
\hline Waist-hip ratio, mean \pm SD & $0.89 \pm 0.08$ \\
\hline Fasting glucose, mean $\pm \mathrm{SD}(\mathrm{mg} / \mathrm{dL})$ & $99.7 \pm 15.2$ \\
\hline Total cholesterol, mean \pm SD (mg/dL) & $212.5 \pm 46.5$ \\
\hline LDL cholesterol, median, IQR (mg/dL) & $126.0,67.0$ \\
\hline HDL cholesterol, mean $\pm \mathrm{SD}(\mathrm{mg} / \mathrm{dL})$ & $54.7 \pm 12.3$ \\
\hline Triglyceride, median, IQR (mg/dL) & $148.0 \pm 48.5$ \\
\hline Creatinine, median, IQR (mg/dL) & $0.8,0.2$ \\
\hline Potassium, mean $\pm \mathrm{SD}(\mathrm{mmol} / \mathrm{L})$ & $4.2 \pm 0.4$ \\
\hline Uric acid, mean $\pm \mathrm{SD}(\mathrm{mg} / \mathrm{dL})$ & $4.3 \pm 1.2$ \\
\hline
\end{tabular}

Abbreviations: ABPM, ambulatory blood pressure monitoring; DBP, diastolic blood pressure; HDL, high-density lipoprotein; IQR, interquartile range; LDL, lowdensity lipoprotein; SBP, systolic blood pressure; SD, standard deviation. night DBP $(\mathrm{r}=0.3, P<0.05)$, and MBPS $(\mathrm{r}=0.3, P<0.05$, Figure 1).

\section{Discussion}

HT is not only a significant cardiovascular risk factor by itself but also usually accompanies other cardiovascular risk factors such as abdominal obesity, DM, and hyperlipidemia. ${ }^{16}$ Occurrence of these pathological conditions together is called "metabolic syndrome" and is associated with a strong likelihood of suffering from cardiovascular diseases. ${ }^{7}$ All these pathologies are thought to occur as a result of the common pathophysiological pathway, IR. ${ }^{7}$

Genetic, environmental, and nutritional factors seem to interfere with the presence and degree of IR. Increased abdominal fat may lead to increased resistance to insulin, resulting in hyperinsulinemia and diabetic tendencies. Increased fat tissue and various other nutritional factors are speculated to increase IR and incidence of related complications. One such factor is increased fructose intake, which leads to hyperuricemia by increasing insulin resistance and abdominal fat tissue, a condition classically associated with gouty arthritis but usually not considered a significant problem if there are no arthritic symptoms. ${ }^{10}$

However, in this study, we found that hyperuricemia is closely associated with HT, diabetic tendencies, and abdominal obesity. Subjects with a non-dipping BP pattern had higher uric acid levels, WHR, FBG, and Tcol and LDL cholesterol levels compared with their dipper counterparts (Table 2). Risk analysis revealed that increased uric acid levels were a significant risk factor for non-dipper BP pattern $(P<0.0001$, odds ratio $=8.1,95 \%$ confidence interval $=1.9-33.7)$. Also, patients in the highest quadrant for uric acid levels had higher FBG, LDL cholesterol, WHR, MBPS, and night DBP compared with those in the lowest quadrant (Table 3). All these results signify the coexistence of hyperuricemia with well-known cardiovascular risk factors such as DM, hyperlipidemia, obesity, and HT, but it is unknown whether hyperuricemia is the reason for or the result of this.

In a study by Wasada et al of 160 subjects, patients with uric acid levels in the highest quadrant had the highest body mass index and FBG as well as a hyperlipidemic profile. ${ }^{17}$ Similarly, Lin et al reported that patients with MetS have a tendency to hyperuricemia and that uric acid levels are correlated with insulin levels, TGs, the homeostatic model assessment of insulin resistance, both SBP and DBP, and abdominal obesity. ${ }^{18}$ Korpachev et al analyzed a group of 90 patients and reported that uric acid was related to abdominal obesity and IR. ${ }^{19}$ Further, some large-scale epidemiological 
Table 2 Comparison of dipper and non-dipper patients

\begin{tabular}{|c|c|c|c|}
\hline & Dipper group $(n=45)$ & Non-dipper group $(n=36)$ & $P$ \\
\hline $\operatorname{Sex}(M / F)$ & $8 / 37$ & $12 / 24$ & 0.088 \\
\hline Age, mean \pm SD (years) & $56.6 \pm 5.9$ & $60.7 \pm 12.1$ & 0.053 \\
\hline Office SBP, median, IQR (mmHg) & $160,20.0$ & 160,20 & 0.828 \\
\hline Office DBP, median, IQR (mmHg) & $110,20.0$ & 110,10 & 0.796 \\
\hline ABPM daytime SBP, mean $\pm \mathrm{SD}(\mathrm{mmHg})$ & $155.8 \pm 10.7$ & $154.6 \pm 17.6$ & 0.723 \\
\hline ABPM daytime $\mathrm{DBP}$, mean $\pm \mathrm{SD}(\mathrm{mmHg})$ & $91.3 \pm 6.6$ & $88.9 \pm 8.4$ & 0.176 \\
\hline ABPM night SBP, median, IQR (mmHg) & $131.6,21.4$ & $140.6,17.4$ & 0.0001 \\
\hline $\mathrm{ABPM}$ night $\mathrm{DBP}$, mean $\pm \mathrm{SD}(\mathrm{mmHg})$ & $59.7 \pm 5.6$ & $67.6 \pm 8.8$ & 0.0001 \\
\hline ABPM 24-hour SBP, mean \pm SD (mmHg) & $151.2 \pm 10.2$ & $153.1 \pm 16.5$ & 0.545 \\
\hline ABPM 24-hour DBP, mean \pm SD $(\mathrm{mmHg})$ & $84.9 \pm 6.0$ & $84.7 \pm 8$ & 0.856 \\
\hline Morning blood pressure surge, mean $\pm \mathrm{SD}(\mathrm{mmHg})$ & $37.4 \pm 7.1$ & $38.3 \pm 9.7$ & 0.641 \\
\hline Body mass index, mean $\pm \mathrm{SD}\left(\mathrm{kg} / \mathrm{m}^{2}\right)$ & $29.4 \pm 3.9$ & $28.9 \pm 4.0$ & 0.605 \\
\hline Waist-hip ratio, mean \pm SD & $0.87 \pm 0.06$ & $0.92 \pm 0.09$ & 0.003 \\
\hline Fasting glucose, mean $\pm \mathrm{SD}(\mathrm{mg} / \mathrm{dL})$ & $94.6 \pm 13.9$ & $106.1 \pm 14.5$ & 0.001 \\
\hline Total cholesterol, mean \pm SD (mg/dL) & $184.3 \pm 34.3$ & $237.4 \pm 4 I .6$ & 0.0001 \\
\hline LDL cholesterol, median, IQR (mg/dL) & $97.0,35.0$ & $153.0,45.5$ & 0.0001 \\
\hline $\mathrm{HDL}$ cholesterol, mean $\pm \mathrm{SD}(\mathrm{mg} / \mathrm{dL})$ & $55.1 \pm 12.7$ & $54.3 \pm 12.0$ & 0.813 \\
\hline Triglyceride, median, IQR (mg/dL) & $147.0,33.0$ & $151.0,55.0$ & 0.417 \\
\hline Creatinine, median, IQR (mg/dL) & $0.8,0.2$ & $0.8,0.15$ & 0.101 \\
\hline Potassium, mean $\pm \mathrm{SD}(\mathrm{mmol} / \mathrm{L})$ & $4.2 \pm 0.3$ & $4.3 \pm 0.5$ & 0.232 \\
\hline Uric acid, mean $\pm \mathrm{SD}(\mathrm{mg} / \mathrm{dL})$ & $3.7 \pm 0.9$ & $5.0 \pm 1.3$ & 0.0001 \\
\hline Hyperuricemia, median, IQR ( $>6$ mg/dL, n, \%) & $2,4.4$ & $13,36.1$ & 0.0001 \\
\hline
\end{tabular}

Abbreviations: ABPM, ambulatory blood pressure monitoring; DBP, diastolic blood pressure; HDL, high-density lipoprotein; IQR, interquartile range; LDL, low-density lipoprotein; SBP, systolic blood pressure; SD, standard deviation.

studies have reported an association between hyperuricemia, MetS, and abdominal obesity. ${ }^{20-22}$

Hyperuricemia may be a secondary result of decreased renal uric acid clearance in some patients. ${ }^{20-22}$ However, some studies have reported increased uric acid production in patients with MetS who have normal renal function. For example, See et al analyzed data on 28,745 subjects and reported that hyperuricemia is only weakly associated with renal function but is strongly associated with MetS with or without a low glomerular filtration rate. ${ }^{23}$ The authors also reported that the main cause of hyperuricemia was increased production rather than decreased clearance of uric acid. Another possible explanation for this elevation might be increased renal tubular reabsorption due to hyperinsulinemia. ${ }^{24}$ Supporting this theory, we found a close association between the MetS components, FBG, WHR, and uric acid levels in a group of patients with normal renal function.

Another important finding of our study is the close association of hyperuricemia with non-dipping pattern and increased MBPS. Non-dipping patients are known to have a higher degree of cardiovascular risk compared with those who dip. It is well known that there is a tendency for increased occurrence of myocardial infarction, sudden death, and hemorrhagic or ischemic stroke 6 and 9 am, just after waking from sleep. ${ }^{5,6}$ This is thought to be secondary to increased MBPS in hypertensive individuals. Increased vascular resistance secondary to increased sympathetic and renin-angiotensin system activities have also been speculated to be the main underlying reason for increased MBPS. ${ }^{25}$ Similarly, increased cortisol levels (as a result of circadian rhythm) may also increase vascular resistance and cause a hypertensive attack. ${ }^{26}$ Moreover, patients with MetS might be more prone to increased MBPS simply because of their IR. Hyperinsulinemia increases sympathetic activity and intravascular volume as well as causing ED and angiotensin II receptor upregulation. ${ }^{27-30}$

Thus, at this stage, we think that uric acid might closely interact with every component of MetS. We found that MBPS was clearly related to the degree of abdominal obesity and hyperuricemia, while we also found a relationship between uric acid levels, WHR, and FBG. Patients with increased uric acid levels also had higher MBPS. Supportive of our findings is a recent analysis of the Framingham Heart Study by Sundström et al, who similarly reported that serum uric acid level was an independent predictor of HT. ${ }^{31}$ Zoppini et al, Kim et al, and Holme et al also reported that increased uric acid levels are independently associated with increased cardiovascular mortality, stroke, and congestive 
Table 3 Comparison of patients in lowest and highest uric acid quadrants

\begin{tabular}{|c|c|c|c|}
\hline & Lowest uric acid quadrant $(n=20)$ & Highest uric acid quadrant $(n=20)$ & $\mathbf{P}$ \\
\hline $\operatorname{Sex}(M / F)$ & $6 / 14$ & $4 / 16$ & 0.358 \\
\hline Age, mean \pm SD (years) & $59.8 \pm 10.6$ & $57.2 \pm 7.8$ & 0.395 \\
\hline Office SBP, median, IQR (mmHg) & $160.00,31.25$ & $160.00,20.00$ & 0.874 \\
\hline Office DBP, median, IQR (mmHg) & $110.00,13.75$ & $110.00,25.00$ & 0.696 \\
\hline ABPM daytime SBP, mean \pm SD $(\mathrm{mmHg})$ & $158.2 \pm 13.1$ & $159.2 \pm 18.6$ & 0.853 \\
\hline ABPM daytime $\mathrm{DBP}$, mean $\pm \mathrm{SD}(\mathrm{mmHg})$ & $93.1 \pm 3.4$ & $92.8 \pm 9.4$ & 0.891 \\
\hline ABPM night SBP, median, IQR (mmHg) & $138.00,14.50$ & $145.00,33.75$ & 0.276 \\
\hline $\mathrm{ABPM}$ night $\mathrm{DBP}$, mean $\pm \mathrm{SD}(\mathrm{mmHg})$ & $61.4 \pm 4.9$ & $67.5 \pm 8.5$ & 0.013 \\
\hline ABPM 24-hour SBP, mean \pm SD (mmHg) & $155.4 \pm 11.7$ & $157.1 \pm 18.6$ & 0.577 \\
\hline ABPM 24-hour DBP, mean \pm SD (mmHg) & $86.7 \pm 3.3$ & $87.7 \pm 8.4$ & 0.656 \\
\hline Morning blood pressure surge, mean $\pm \mathrm{SD}(\mathrm{mmHg})$ & $35.6 \pm 7.2$ & $44.3 \pm 9.8$ & 0.003 \\
\hline Body mass index, mean $\pm \mathrm{SD}\left(\mathrm{kg} / \mathrm{m}^{2}\right)$ & $28.9 \pm 3.4$ & $29.7 \pm 3.5$ & 0.465 \\
\hline Waist-hip ratio, mean \pm SD & $0.85 \pm 0.06$ & $0.92 \pm 0.09$ & 0.01 \\
\hline Fasting glucose, mean $\pm \mathrm{SD}(\mathrm{mg} / \mathrm{dL})$ & $91.6 \pm 16.7$ & $108.3 \pm 13.9$ & 0.001 \\
\hline Total cholesterol, mean \pm SD (mg/dL) & $195.1 \pm 39.9$ & $223.6 \pm 35.8$ & 0.058 \\
\hline LDL cholesterol, median, IQR (mg/dL) & $123.0,57.0$ & $148.0,68.0$ & 0.017 \\
\hline $\mathrm{HDL}$ cholesterol, mean $\pm \mathrm{SD}(\mathrm{mg} / \mathrm{dL})$ & $52.1 \pm 13.3$ & $51.1 \pm 11.4$ & 0.850 \\
\hline Triglyceride, median, IQR (mg/dL) & $144.0,55.0$ & I55.0, 34.5 & 0.634 \\
\hline Creatinine, median, IQR (mg/dL) & $0.85,0.25$ & $0.8,0.1$ & 0.118 \\
\hline Potassium, mean \pm SD (mmol/L) & $4.1 \pm 0.3$ & $4.2 \pm 0.3$ & 0.240 \\
\hline Uric acid, mean \pm SD (mg/dL) & $2.9 \pm 0.3$ & $6.1 \pm 0.7$ & 0.0001 \\
\hline Non-dipper, n, \% & $4.0,20.0$ & $16.0,80.0$ & 0.0001 \\
\hline
\end{tabular}

Abbreviations: ABPM, ambulatory blood pressure monitoring; DBP, diastolic blood pressure; HDL, high-density lipoprotein; IQR, interquartile range; LDL, low-density lipoprotein; SBP, systolic blood pressure; SD, standard deviation.

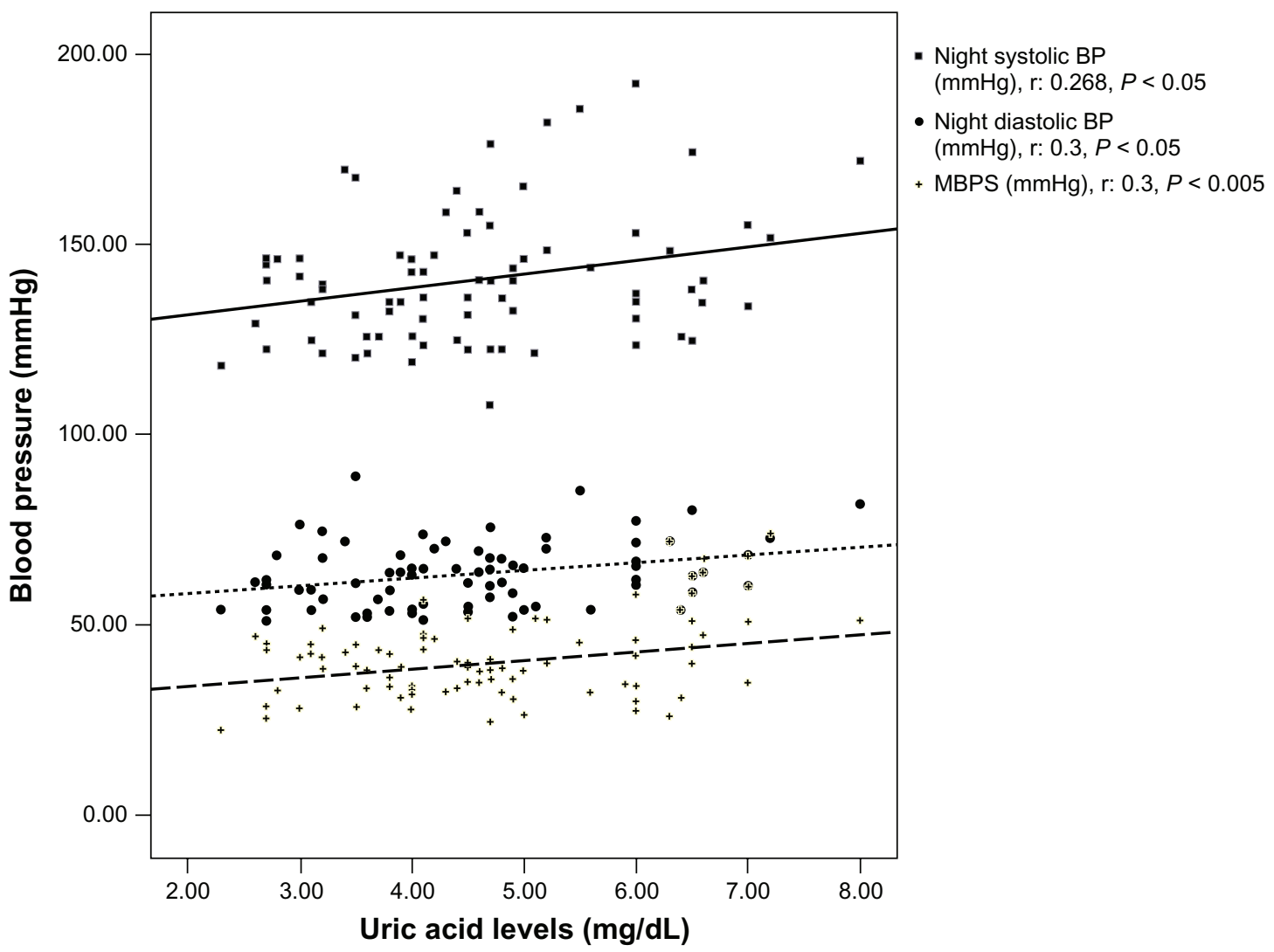

Figure I Blood pressure - uric acid relationship.

Abbreviations: BP, blood pressure; MBPS, morning blood pressure surge. 
heart failure in three different epidemiological studies. ${ }^{32-34}$ We think that increased uric acid levels may induce IR and abdominal obesity, two conditions that increase uric acid levels with a positive feedback mechanism. All three of these conditions increase BP separately or in additive manner through some common mechanisms. As such, we feel that evaluation of hypertensive patients should also include assessment of uric acid levels and anthropometric measurements, as abdominal obesity and hyperuricemia seem to be closely related with undesired BP patterns, and these assessments may alert the clinician to any problems needing treatment.

\section{Author contributions}

Emre Tutal is the main author of this article. Derun Taner Ertugrul, Burak Sayin, Avsin Ibis, Siren Sezer, and Nurhan Özdemir assisted in collecting study data and writing the article.

\section{Disclosure}

The authors declare no conflicts of interest in this work.

\section{References}

1. Lewington S, Clarke R, Qizilbash N, Peto R, Collins R; Prospective Studies Collaboration. Age-specific relevance of usual blood pressure to vascular mortality: a meta-analysis of individual data for one million adults in 61 prospective studies. Lancet. 2002;360(9349):1903-1913.

2. Kario K, Schwartz JE, Gerin W, Robayo N, Maceo E, Pickering TG. Psychological and physical stress-induced cardiovascular reactivity and diurnal blood pressure variation in women with different work shifts. Hypertens Res. 2002;25(4):543-551.

3. Kario K, James GD, Marion R, Ahmed M, Pickering TG. The influence of work- and home-related stress on the levels and diurnal variation of ambulatory blood pressure and neurohumoral factors in employed women. Hypertens Res. 2002;25(4):499-506.

4. Kawasaki T, Cugini P, Uezono K, et al. Circadian variations of total renin, active renin, plasma renin activity and plasma aldosterone in clinically healthy young subjects. Horm Metab Res. 1990;22(12):636-639.

5. Muller JE, Tofler GH, Stone PH. Circadian variation and triggers of onset of acute cardiovascular disease. Circulation. 1989;79(4):733-743.

6. Marler JR, Price TR, Clark GL, et al. Morning increase in onset of ischemic stroke. Stroke. 1989;20(4):473-476.

7. Expert Panel on Detection, Evaluation, and Treatment of High Blood Cholesterol in Adults. Executive Summary of The Third Report of The National Cholesterol Education Program (NCEP) Expert Panel on Detection, Evaluation, and Treatment of High Blood Cholesterol in Adults (Adult Treatment Panel III). JAMA. 2001;285(19):2486-2497.

8. Katsiki N, Papanas N, Fonseca VA, Maltezos E, Mikhailidis DP. Uric acid and diabetes: is there a link? Curr Pharm Des. Epub December 26, 2012.

9. Cohen E, Krause I, Fraser A, Goldberg E, Garty M. Hyperuricemia and metabolic syndrome: lessons from a large cohort from Israel. Isr Med Assoc J. 2012;14(11):676-680.

10. Borges RL, Ribeiro AB, Zanella MT, Batista MC. Uric acid as a factor in the metabolic syndrome. Curr Hypertens Rep. 2010;12(2):113-119.

11. Jalal DI, Chonchol M, Chen W, Targher G. Uric acid as a target of therapy in CKD. Am J Kidney Dis. 2013;61(1):134-146.
12. Chobanian AV, Bakris GL, Black HR, et al; Joint National Committee on Prevention, Detection, Evaluation, and Treatment of High Blood Pressure; National Heart, Lung, and Blood Institute; National High Blood Pressure Education Program Coordinating Committee. Seventh report of the Joint National Committee on Prevention, Detection, Evaluation, and Treatment of High Blood Pressure. Hypertension. 2003;42(6):1206-1252.

13. White WB, Larocca GM. Improving the utility of the nocturnal hypertension definition by using absolute sleep blood pressure rather than the "dipping" proportion. Am J Cardiol. 2003;92(21):1439-1441.

14. Kario K, Pickering TG, Umeda Y, et al. Morning surge in blood pressure as a predictor of silent and clinical cerebrovascular disease in elderly hypertensives: a prospective study. Circulation. 2003;107(10): 1401-1406.

15. Snijder MB, Zimmet PZ, Visser M, Dekker JM, Seidell JC, Shaw JE. Independent and opposite associations of waist and hip circumferences with diabetes, hypertension and dyslipidemia: the AusDiab Study. Int J Obes Relat Metab Disord. 2004;28(3):402-409.

16. Kaplan NM. Kaplan's Clinical Hypertension, 8th ed. Philadelphia, PA: Lippincott Williams \& Wilkins; 2002.

17. Wasada T, Katsumori K, Saeki A, Iwatani M. [Hyperuricemia and insulin resistance]. Nippon Rinsho. 1996;54(12):3293-3296. Japanese.

18. Lin JD, Chiou WK, Chang HY, Liu FH, Weng HF. Serum uric acid and leptin levels in metabolic syndrome: a quandary over the role of uric acid. Metabolism. 2007;56(6):751-756.

19. Korpachev VV, Hurina NM, Korpacheva TI, Shuprovych AA, Mosendz IO. [Peculiarities of uric acid balance disorders in patients with type 2 diabetes and metabolic syndrome.] Fiziol $\mathrm{Zh}$. 2009:55(3):133-140. Ukrainian.

20. Schmidt MI, Duncan BB, Watson RL, Sharrett AR, Brancati FL, Heiss G. A metabolic syndrome in whites and African-Americans. The Atherosclerosis Risk in Communities baseline study. Diabetes Care. 1996;19(5):414-418.

21. Yoo TW, Sung KC, Shin HS, et al. Relationship between serum uric acid concentration and insulin resistance and metabolic syndrome. Circ J. 2005;69(8):928-933.

22. Onat A, Uyarel $\mathrm{H}$, Hergenç $\mathrm{G}$, et al. Serum uric acid is a determinant of metabolic syndrome in a population-based study. Am J Hypertens. 2006:19(10):1055-1062.

23. See LC, Kuo CF, Chuang FH, et al. Serum uric acid is independently associated with metabolic syndrome in subjects with and without a low estimated glomerular filtration rate. J Rheumatol. 2009;36(8): 1691-1698.

24. Quiñones Galvan A, Natali A, Baldi S, et al. Effect of insulin on uric acid excretion in humans. Am J Physiol. 1995;268(1 Pt 1):E1-E5.

25. Kario K, Pickering TG, Hoshide S, et al. Morning blood pressure surge and hypertensive cerebrovascular disease: role of the alpha adrenergic sympathetic nervous system. Am J Hypertens. 2004;17(8): 668-675.

26. Otto ME, Svatikova A, Barretto RB, et al. Early morning attenuation of endothelial function in healthy humans. Circulation. 2004;109(21): 2507-2510.

27. Hall JE, Louis K. Dahl Memorial Lecture. Renal and cardiovascular mechanisms of hypertension in obesity. Hypertension. 1994;23(3): 381-394.

28. Reaven GM, Lithell H, Landsberg L. Hypertension and associated metabolic abnormalities - the role of insulin resistance and the sympathoadrenal system. N Engl J Med. 1996;334(6):374-381.

29. Rocchini AP, Katch V, Kveselis D, et al. Insulin and renal sodium retention in obese adolescents. Hypertension. 1989;14(4):367-374.

30. Steinberg HO, Chaker H, Leaming R, Johnson A, Brechtel G, Baron AD. Obesity/insulin resistance is associated with endothelial dysfunction. Implications for the syndrome of insulin resistance. J Clin Invest. 1996; 97(11):2601-2610.

31. Sundström J, Sullivan L, D’Agostino RB, Levy D, Kannel WB, Vasan RS. Relations of serum uric acid to longitudinal blood pressure tracking and hypertension incidence. Hypertension. 2005;45(4):28-33. 
32. Zoppini G, Targher G, Negri C, et al. Elevated serum uric acid concentrations independently predict cardiovascular mortality in type 2 diabetic patients. Diabetes Care. 2009;32(9):1716-1720.

33. Kim SY, Guevara JP, Kim KM, Choi HK, Heitjan DF, Albert DA. Hyperuricemia and risk of stroke: a systematic review and metaanalysis. Arthritis Rheum. 2009;61(7):885-892.
34. Holme I, Aastveit AH, Hammar N, Jungner I, Walldius G. Uric acid and risk of myocardial infarction, stroke and congestive heart failure in 417,734 men and women in the Apolipoprotein MOrtality RISk study (AMORIS). J Intern Med. 2009;266(6):558-570.

\section{Publish your work in this journal}

The International Journal of Nephrology and Renovascular Disease is an international, peer-reviewed open-access journal focusing on the pathophysiology of the kidney and vascular supply. Epidemiology, screening, diagnosis, and treatment interventions are covered as well as basic science, biochemical and immunological studies. The journal welcomes original research, clinical studies, reviews \& evaluations, expert opinion and commentary, case reports and extended reports. The manuscript management system is completely online and includes a very quick and fair peerreview system, which is all easy to use. Visit http://www.dovepress.com/ testimonials.php to read real quotes from published authors

Submit your manuscript here: http://www.dovepress.com/international-journal-of-nephrology-and-renovascular-disease-journal 